February 2019 Volume 6 Issue 1

(C) All rights are reserved by Grisa A, et al.

\title{
3D Model Simulation and Patient Surgery in Guided Bone Regeneration
}

\begin{abstract}
The anterior maxilla has traditionally been a challenge when it comes to successfully placing dental implants. This is due to a combination of poor bone quality, ridge atrophy and bone resortion following extraction. Many techniques are available today for the experienced surgeon to rebuild lost bone, including guided bone regeneration (GBR). Despite GBR being a predictable procedure, complications can and do arise that may compromise outcomes. The most frequent of these include membrane exposure, fenestration/dehiscence, infection, graft particle leakage, collapse of the grafted site and excessive bleeding. However, careful pre-surgical planning is crucial and will reduce risk and incidence of complications. Cone Beam Computed Tomography (CBCT) provides greater detail and has become a commonly used diagnostic tool for implant treatment planning. Patient 3D printed modelscan be used to gain insight and become familiar with a patient's exact anatomy prior to the surgical procedure. Using such models can aid in reducing surgical time, limiting the amount of soft tissue manipulation, familia rizing the surgeon with the patient's specific anatomy, therefore reducing the risk of intra-operative complications, and decreasing the potential for emor. The pumose of this article is to report on the use of a 3D printed model to familiarize with the anatomy of the patient prior to the surgery to plan and avoid possible complications.
\end{abstract}

\section{Introduction}

The anterior maxilla is demanding and challenging when it comes to establishing clinical success while placing dental implants. This is due to a combination of esthetic expectations, poor bone quality, ridge atrophy and bone resorption following extraction. Various techniques are available today for experienced surgeons to reconstruct lost bone, such as Autologous onlay block grafts [1], allograft block grafts [2], distraction-osteogenesis and guided bone regeneration (GBR) $[3,4]$. Studies in animals and humans have shown that GBR is an effective technique to augment atrophic ridges.

Despite GBR being a predictable procedure, complications can arise that may compromise the final outcomes of this procedure. The most frequent complications include membrane exposure, fenestration or dehiscence, infection, graft particle leakage, collapse of the grafted site and excessive bleeding $[5,6]$. Although GBR has a high rate of success, it is surgically challenging and presents various risks and difficulties. However careful pre-surgical planning is crucial and will reduce the risk and incidence of complications.

Cone Beam Computed Tomography (CBCT) provides greater detailed images of the bone and has become a common diagnostic tool for implant treatment planning. In spite of these advantages, it can still be challenging to convert the two-dimensional cross sectional images from $\mathrm{CBCT}$ into the three-dimensional geometrical structure of the atrophic ridge. For this purpose 3D printing technology has been introduced in dentistry as a useful and cost effective tool for educational purposes and to improve pre-surgical preparation $[7,8]$. More recent advances in digital technology have made 3D printing
Journal of Oral Biology

\author{
Grisa A, Maurino CD, Valladares A, Muchhala S and \\ Yu PY*
}

Arthur Ashman Department of Periodontology and Implant Dentistry, New York University College of Dentistry, USA

\section{*Address for Correspondence}

Yu PY, Arthur Ashman Department of Periodontology and Implant Dentistry, New York University College of Dentistry, New York 10010, USA; E-mail: ycy233@nyu.edu

\section{Submission: 03 September, 2018}

Accepted: 25 February, 2019

Published: 27 February, 2019

Copyright: (c) 2018 Grisa A, et al. This is an open access article distributed under the Creative Commons Attribution License, which permits unrestricted use, distribution, and reproduction in any medium, provided the original work is properly cited.

more accessible and more economical, gaining ground in mainstream dentistry. 3D-printed models can be used to gain insight, carefully study and become familiar with the exact anatomy of the patient's maxillary bone prior to any surgical procedures [9].

Furthermore, 3D models can be used for preoperative simulation of the surgical procedure itself, which is advantageous to the surgeon who will perform the procedure. Using such models can aid in reducing surgical time, limiting the amount of soft tissue manipulation, familiarizing the surgeon with the patient's specific anatomy, reducing the risk of intra-operative complications, and decreasing the potential for errors [10-13]. The purpose of this case report is to report the use of a $3 \mathrm{D}$ model prior to a ridge augmentation procedure to get familiar with the patient's maxillary anatomy and

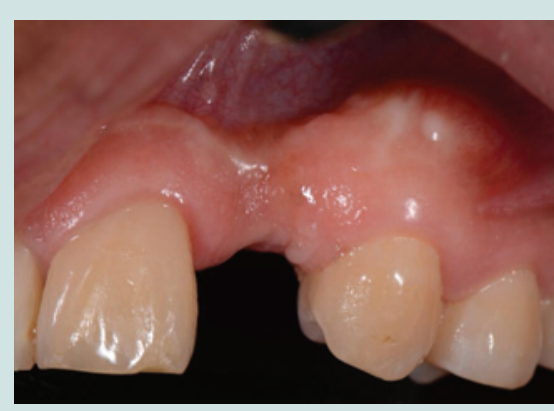

Figure 1: Pre surgical buccal view of the patient site \#10, 11

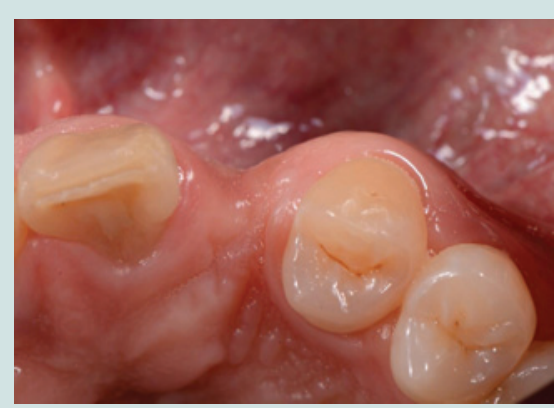

Figure 2: Pre surgical occlusal view of the patient site \#10, 11. 
Citation: Grisa A, Maurino CD, Valladares A, Muchhala S, Yu PY. 3D Model Simulation and Patient Surgery in Guided Bone Regeneration. J Oral Biol. $2019 ; 6(1): 6$

ISSN: $2377-987 X$

Table 1: Comparison of the clinical procedure against the 3D model.

\begin{tabular}{|c|c|c|}
\hline Clinical Procedure & 3D model Simulation & Comments \\
\hline Incision design & ++ & On the model it is possible to design the flap as in patient's mouth \\
\hline Flap elevation & + & Simulation \\
\hline Periosteal releasing incision & + & Material used to simulate soft tissue allows releasing incision \\
\hline Decortication & ++ & Decortication can be performed on the model \\
\hline Membrane Tacking & ++ & Tacking using real tags is possible on the model \\
\hline
\end{tabular}

+: Simulation procedure comparable to the clinical procedure

++: Simulation procedure and tactile sensation comparable to the clinical procedure

plan the treatment to avoid possible complications.

\section{Case Report}

In 2016, a 32-year-old male was referred to the Ashman Department of Periodontology and Implant Dentistry of New York University College of Dentistry. The patient was a non-smoker with an unremarkable medical history. His chief complaint was the missing left lateral incisor that doesn't allow him to smile confidently. He desired a fixed restoration. Tooth \#10 was extracted several years before with the subsequent loss of supporting bone and soft tissue (Figure 1 and 2). A CBCT scan was taken to carefully evaluate the anatomy of the alveolar ridge and revealed a deficient volume of buccolingual crestal bone and the need for a bone regeneration procedure prior to implant placement (Figure 3). Digital Imaging and Communications in Medicine (DICOM) images from the patient's CBCT were then converted to STL files (OsiriX Lite, Geneva, Switzerland) and transferred to a 3D printer (Formlabs, USA) for production of a polymer model of the maxilla. Medical adhesive tape was added to the model to mimic the oral mucosa for a more realistic simulation of the actual surgical environment (Figure 4 and 5). The GBR was performed on the $3 \mathrm{D}$ model prior to treating the patient.

The treatment plan was to first augment the bone volume in the area of tooth \#10 and after four months of healing, the placement of an implant and an immediate provisional restoration.

\section{Surgical procedures}

The bone augmentation procedure was performed as follows. The patient was given a prescription of amoxicillin $2 \mathrm{~g} 1$ hour prior to surgery. Figures 6-22 depict the surgical simulation on the 3D printed model with the corresponding stages in the live surgery.

After anesthesia was performed a full thickness flap was elevated with 2 vertical incisions; one papilla sparing incision distal to tooth \# 9 and one intrasulcular incision distal to \# 11. After decortication, a $2 \mathrm{~mm}$ diameter trephine bur was used to harvest a bone core apical to the area being augmented. A $2 \mathrm{~mm}$ diameter hole with a depth of $3 \mathrm{~mm}$ was made perpendicular to the buccal bone wall to allow the placement of the trephined bone core inside allowing it to be used as tent pole. A CopiOs Pericardium Membrane (Zimmer Biomet, USA www.zimmerbiometdental.com) was secured with three apical tacks (truFIX, ACE Surgical, www.acesurgical.com) and the space was filled with Bio-Oss (Geistlich, CH www.geistlich-na.com). A periosteal releasing incision was made to achieve tension-free closure using resorbable sutures. Figures 23 and 24 show the pre and post operative radiographs of the surgical site.
Following surgery, amoxicillin $500 \mathrm{mg}$ TID for 10 days and chlorhexidine $0.12 \%$ mouth-rinse (PeridexTM, 3M ESPE, www.3MESPE.com) BID for 2 weeks were prescribed. The healing process was uneventful (Figure 25). Figure 26 depicts the final restoration for \#11 after 1 year.

\section{Discussion}

3D-printed models can be used to gain insight and become familiar with a patient's anatomy prior to surgical procedures. Furthermore, 3D models can be used for preoperative simulation of the surgical procedure itself, which is advantageous to the surgeon who will perform the procedure. Using such models can aid in reducing surgical time, limiting the amount of soft tissue manipulation, familiarizing the surgeon with the patient's specific anatomy, reducing the risk of intra-operative complications oand decreasing the potential for error [7].

GBR is surgically challenging and effective training and education is required to ensure successful outcomes. Although considered a predictable procedure, care must be taken so as not to disturb the healing process and to maintain the health and well-being of the patient. Simulation of the procedure on the patient's 3D model can enable seamless execution on the day of surgery leading to a more predictable result. The use of 3D-printed models for such training is also preferable to training on cadavers since it is patient-specific and availability and cost are not limitations [14].

Flap design should be considered prior to surgery and the 3D model allows the surgeon to plan the incisions correctly to maximize visibility and access to the surgical site. Incision design and flap elevation, once made, are irreversible and it is crucial that primary closure without tension can be attained [15].

The periosteum is a dense layer of vascular connective tissue enveloping bone. In GBR a periosteal releasing incision increases the flap elasticity and enables the advancement of the soft tissue over the surgical site to achieve a tension-free [16]. During surgery, a proper manipulation of the periosteum, while achieving primary closure, is essential for the healing of the soft tissues due to the enhanced blood supply provided by the connective tissue above the periosteum. The periosteum is therefore a crucial soft tissue layer that influences the success of implant surgery [17].

A resorbable collagen membrane is then cut to the same shape as the template and placed over the model surgical site. Once the membrane is in the correct position, a tack is positioned apically through the membrane into the $3 \mathrm{D}$ model for stabilization. It is then adjusted to extend 2-3 $\mathrm{mm}$ beyond the augmented area. The graft 
Citation: Grisa A, Maurino CD, Valladares A, Muchhala S, Yu PY. 3D Model Simulation and Patient Surgery in Guided Bone Regeneration. J Oral Biol. 2019; 6(1): 6

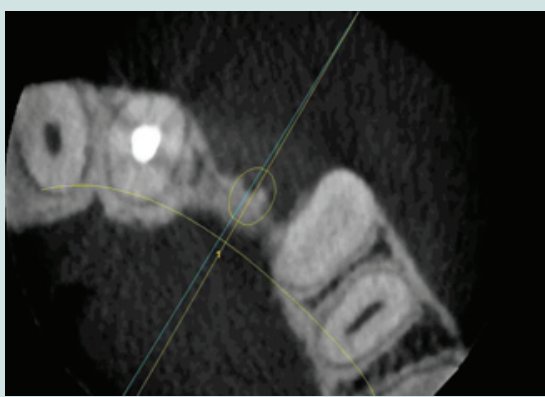

Figure 3: Patient cross sectional view of the defect site \#10, 11.

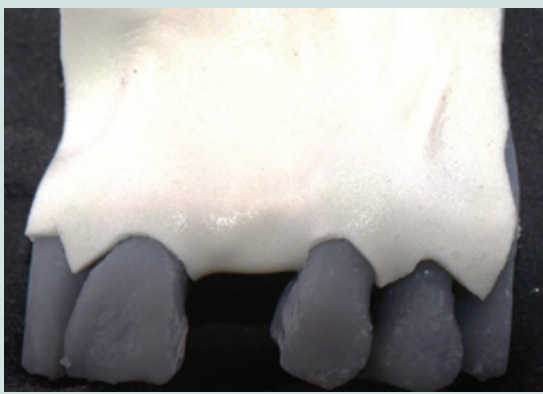

Figure 4: Pre surgical facial view of the 3D model of the patient.

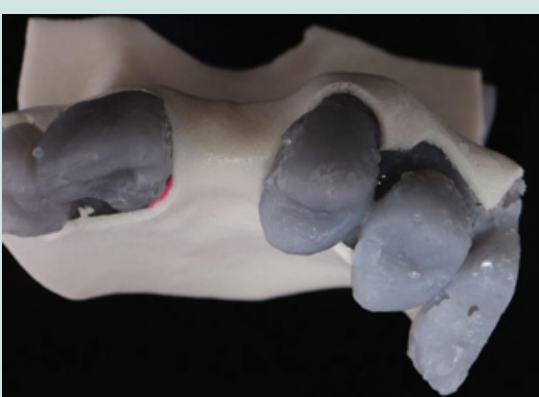

Figure 5: Pre surgical occlusal view of the 3D model of the patient.

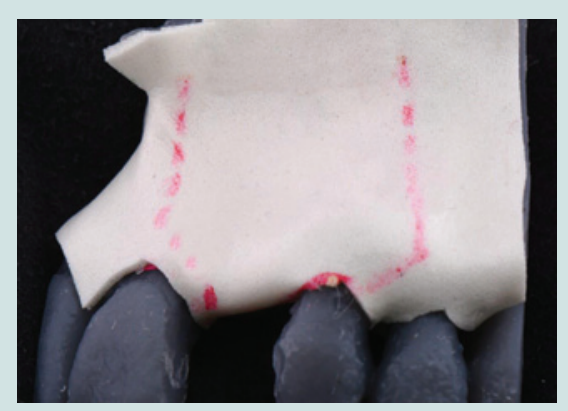

Figure 6: Incision design on 3D model of the patient.

material (e.g. mineralized allograft bone and/or organic bovine bone matrix) is placed and condensed to fill the defect, ensure proper space maintenance, bone contact and support the membrane.

The final accuracy of the 3D printed models is dependent on

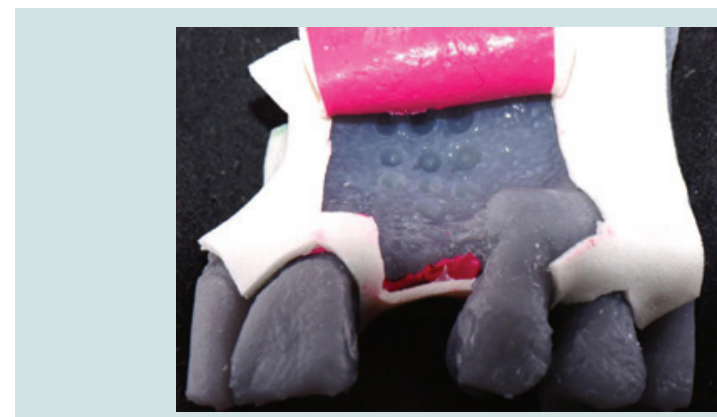

Figure 7: 3D model flap elevation and decortication.

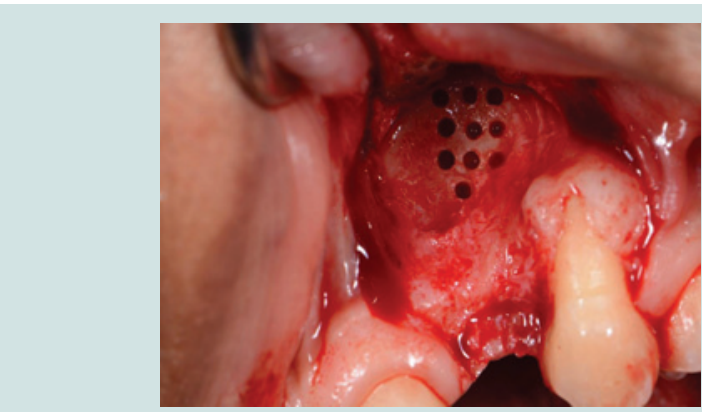

Figure 8: Patient flap elevation and decortication

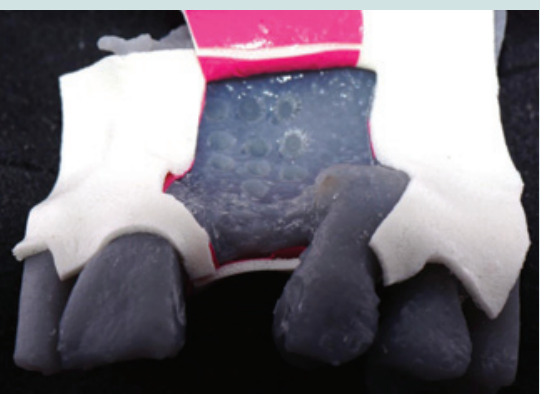

Figure 9: 3D model releasing incision.

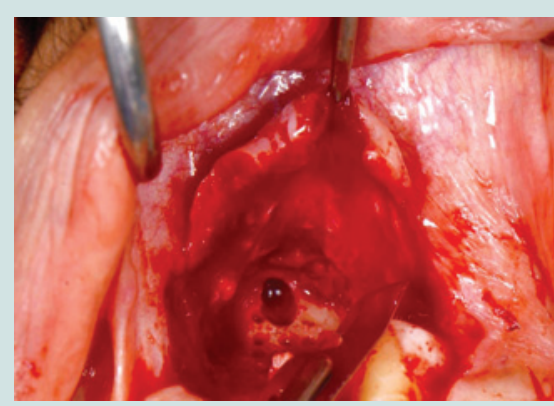

Figure 10: Patient releasing incision.

data taken from the CBCT scan, the segmentation technique used to generate the STL file from the DICOM data and from the printing technique. CBCT accuracy discrepancies are the result of voxel size in association with segmenting, thus affecting the accuracy of the printing process. The study by Szymor et al. showed a high accuracy 
Citation: Grisa A, Maurino CD, Valladares A, Muchhala S, Yu PY. 3D Model Simulation and Patient Surgery in Guided Bone Regeneration. J Oral Biol. 2019; 6(1): 6

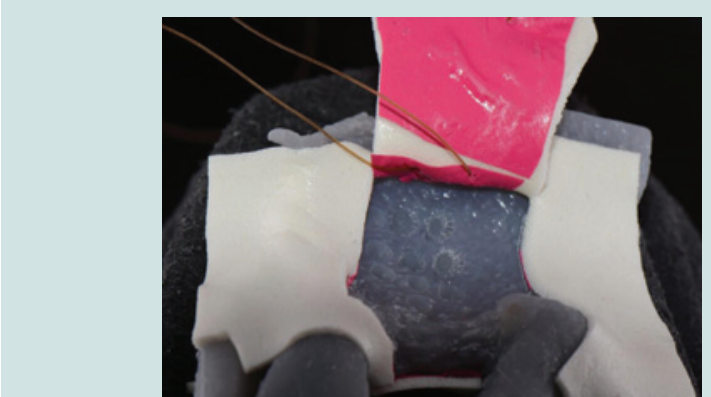

Figure 11: 3D model membrane stabilizing suture.
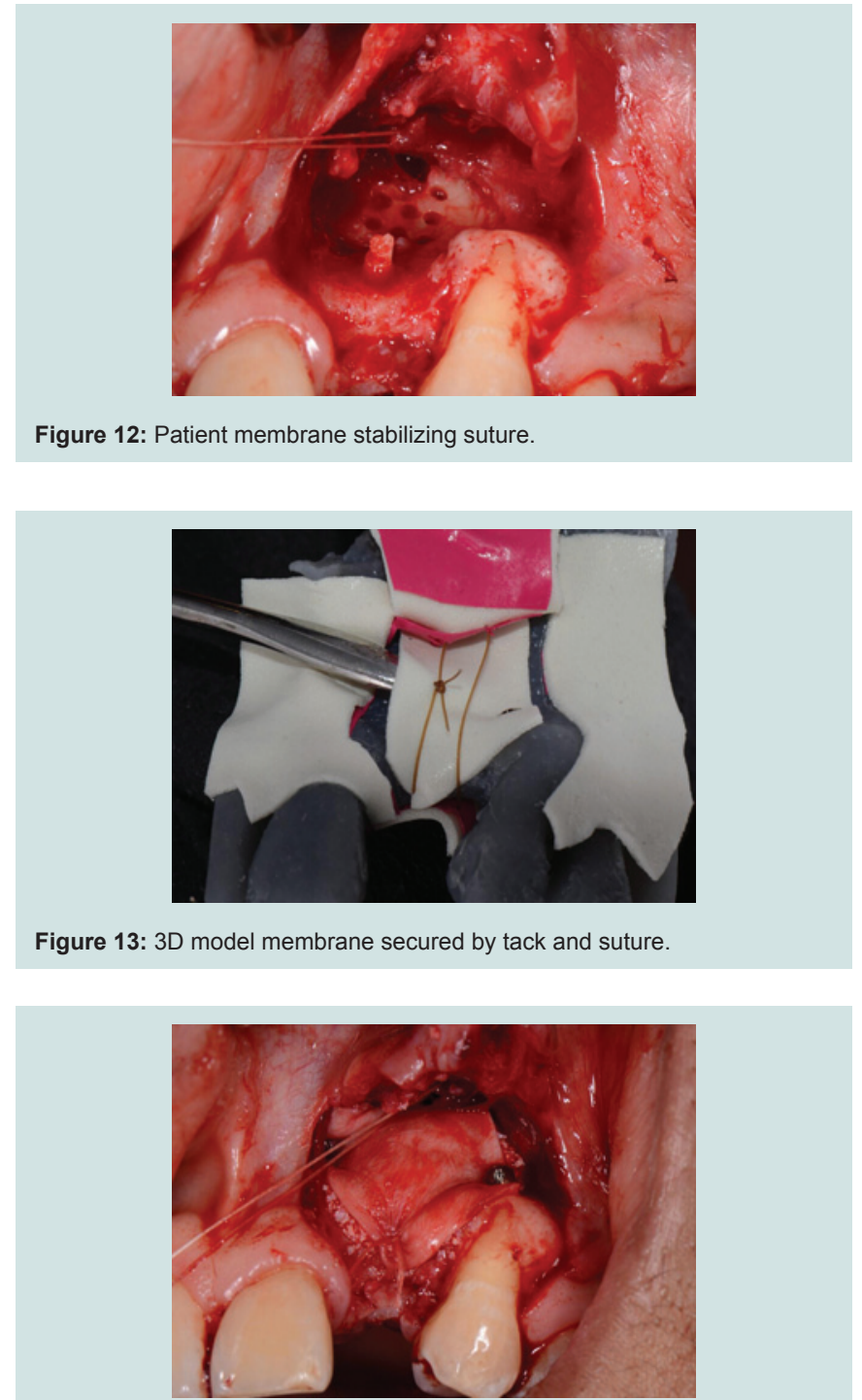

Figure 14: Patient membrane secured by tack and suture.

between the segmented model and the virtual model of $0.05 \pm 0.18$ $\mathrm{mm}$ [18], and the printer used (Form 2, Form labs, USA) in this study has an accuracy of $0.025 \mathrm{~mm}$. This indicates minimal inaccuracy in the final 3D printed models.

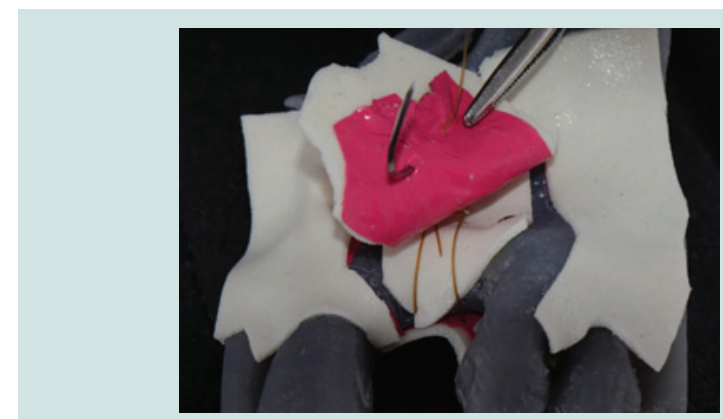

Figure 15: 3D model horizontal mattress suture.

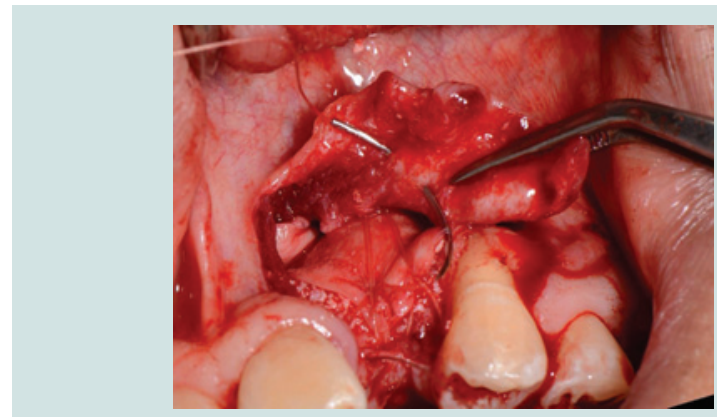

Figure 16: Patient horizontal mattress suture.
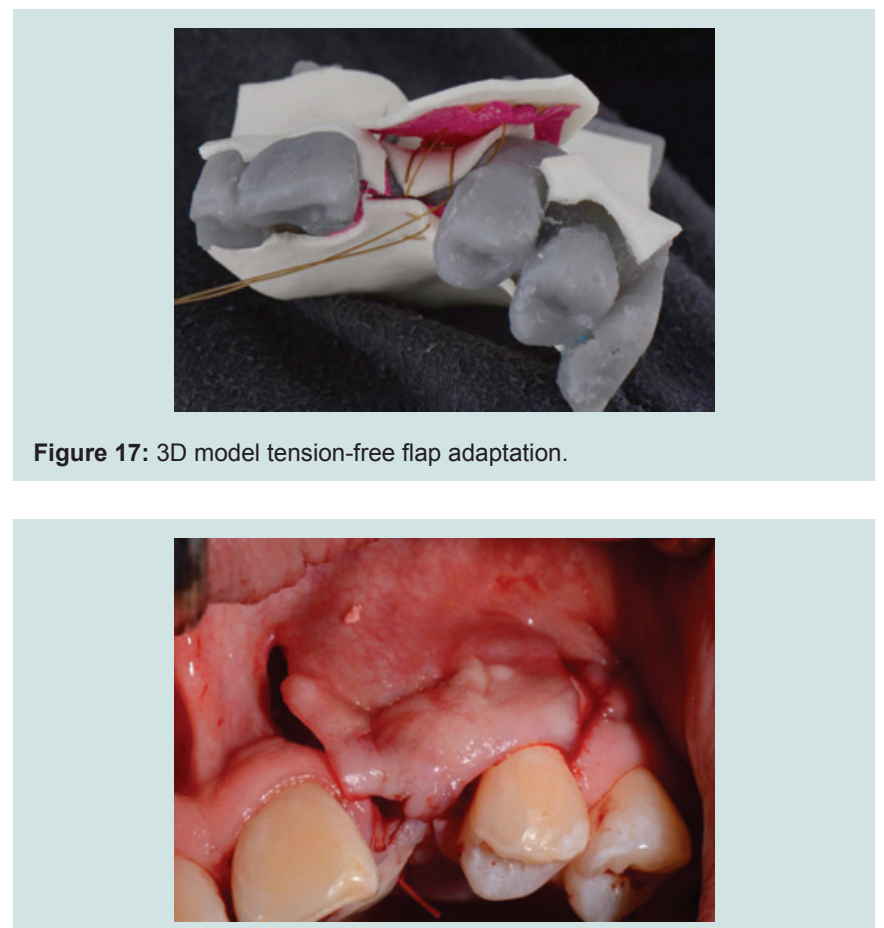

Figure 18: Patient tension free flap adaptation.

As a result, the new 3D model was fabricated with soft tissue elements that present the opportunity to simulate the incision design, flap elevation, decortications, tacking, and graft material placement Table 1. While further improvements are to be made, the revised model presents a significant advantage in implant education 
Citation: Grisa A, Maurino CD, Valladares A, Muchhala S, Yu PY. 3D Model Simulation and Patient Surgery in Guided Bone Regeneration. J Oral Biol. 2019; 6(1): 6

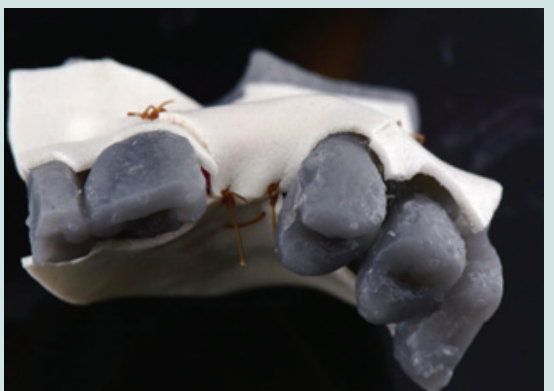

Figure 19: 3D model key sutures from the occlusal view.

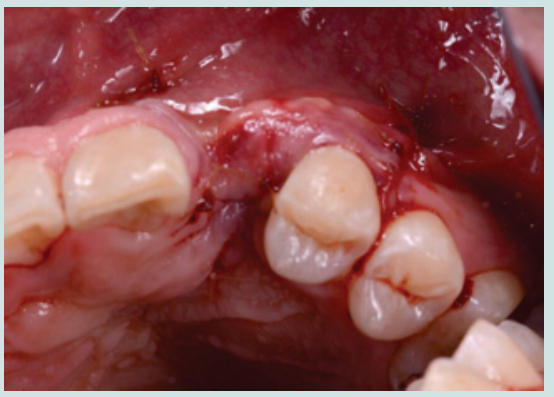

Figure 20: Patient key sutures from the occlusal view.

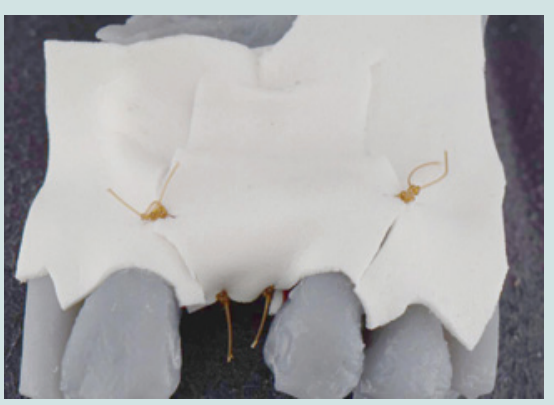

Figure 21: 3D model key sutures from the facial view.

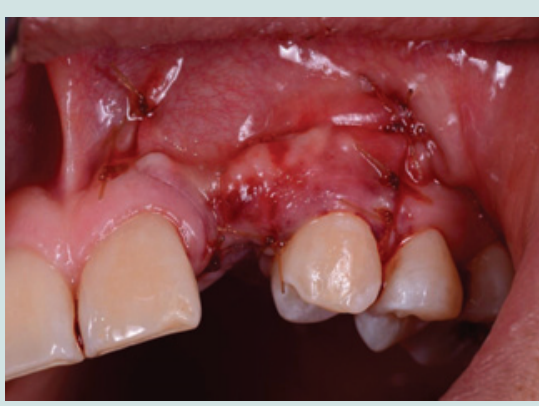

Figure 22: Patient key sutures from the facial view.

and the patients' surgical complications with a positive impact on patient healthcare and management, more data from the Ashman Department of Periodontology and Implant Dentistry will be collected and presented in a future publication.

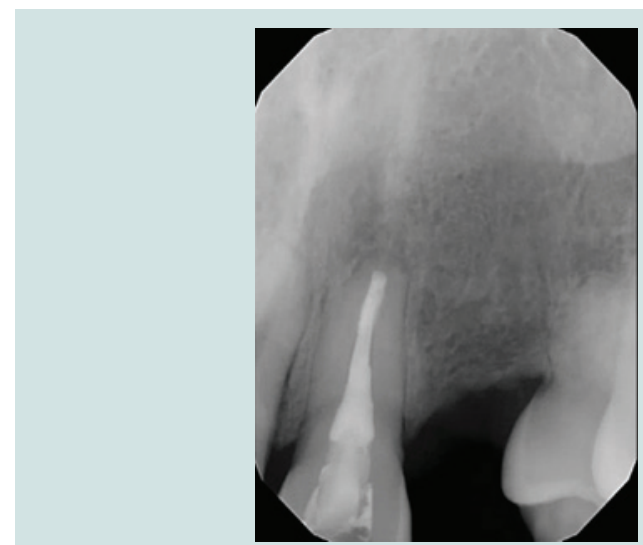

Figure 23: Pre surgical peri-apical of the site \#10, 11.

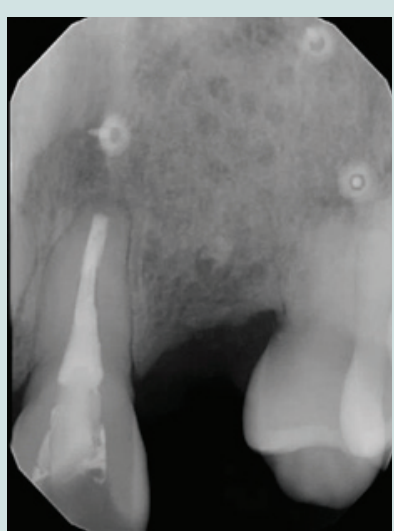

Figure 24: Post surgical peri-apical Apical of site \#10, 11.

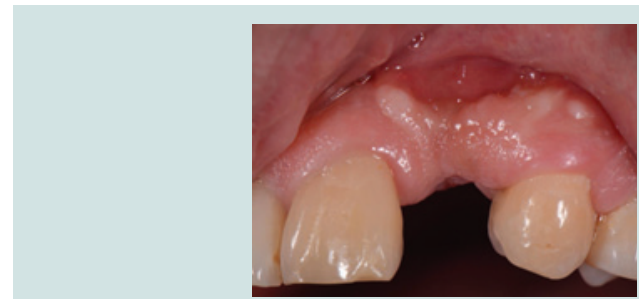

Figure 25: Patient follow-up after 3 months of uneventful healing

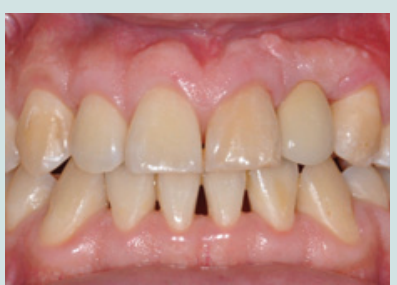

Figure 26: Patient with final restoration after implant placement.

\section{Conclusion}

Guided Bone Regeneration is a predictable but complex procedure. Having an exact three-dimensional model of a patient's 
Citation: Grisa A, Maurino CD, Valladares A, Muchhala S, Yu PY. 3D Model Simulation and Patient Surgery in Guided Bone Regeneration. J Oral Biol. $2019 ; 6(1): 6$

bone defect available for a clinician to study and use for simulation of the guided augmentation procedure is a great advantage compared to relying solely on a CBCT scan, which is viewed in $2 \mathrm{D}$ on a screen.

With the use of patient-specific surgical assistive tools, the risk of surgical errors and outliers can be reduced and operations will be less dependent on the experience of the physician and can lead to a better intervention outcome and a reduction of operation time.

\section{Data Availability}

Clinical data in this study was obtained from the anonymous Implant Database (ID) IRB approved (IRB approval number: H12209-01 A) at the Ashman Department of Periodontology and Implant Dentistry at the New York University College of Dentistry. This data was extracted as de-identified information from the routine treatment of patients. The ID was certified by the Health Insurance Portability and Accountability Act (HIPAA) and approved by the University Committee on the Activities Involving Human Subjects (UCAIHS).

\section{References}

1. Levin L, Nitzan D, Schwartz-Arad D (2007) Success of dental implants placed in intraoral block bone grafts. J Periodontol 78: 8-21.

2. Nissan J, Marilena V, Gross O, Chaushu G (2012) Histomorphometric analysis following augmentation of the anterior atrophic maxilla with cancellous bone block allograft. Int J Oral Maxillofac Implants 27: 84-89.

3. Chiapasco M, Consolo U, Bianchi A, Ronchi P (2004) Alveolar distraction osteogenesis for the correction of vertically deficient edentulous ridges: a multicenter prospective study on humans. Int J Oral Maxillofac Implants 19: 399-407.

4. Dahlin C, Linde A, Gottlow J, Nyman S (1988) Healing of bone defects by guided tissue regeneration. Plast Reconstr Surg 81: 672-676.

5. Froum SJ, Cho SC, Pariente L (2015) A surgical protocol for guided bone regeneration procedures using absorbable membranes to minimize and treat complications. Dental Learning.

6. Fontana F, Maschera E, Rocchietta I, Simion M (2011) Clinical classification of complications in guided bone regeneration procedures by means of a nonresorbable membrane. Int J Perio Restor Dent 31:265-273.

7. Georgantza A, Loomer P, Sang-Choon C, Froum S, Suzuki T, et al. (2016) The Use of 3D Printing in Dental Implant Education. Dent Learning.

8. Dawood A, Marti BM, Sauret-Jackson V, Darwood A (2015) 3D printing in dentistry. Br Dent J 219: 521-529.

9. Schweiger J, Beuer F, Stimmelmayr M, Edelhoff D, Magne P, et al. (2009) Histo-anatomic 3D printing of dental structures. Br Dent J 9: 555-560.

10. Cohen A, Laviv A, Berman P, Nashef R, Abu-Tair J (2009) Mandibular reconstruction using stereolithographic 3-dimensional printing modeling technology. Oral Surg Oral Med Oral Pathol Oral Radiol Endod 108: 661-666.

11. Sze-Wing M, Nizak R, Sai-Chuen Fu, Ki-Wai KH, Qin L, et al. (2016) From the printer: Potential of three-dimensional printing for orthopaedic applications. J Orthop Translation 6: 42-49.

12. Kröger E, Dekiff M, Dirksen D (2016) 3D printed simulation models based on real patient situations for hands-on practice. Eur J Dent Educ 21: e119-e125.

13. Bammani SS, Birajdar PR, Metan SS (2013) Application of CAD and SLA method in dental prosthesis. AMAE Int J Manufacturing Mater Sci 14-18.

14. Banks J (2013) Adding value in additive manufacturing: researchers in the United Kingdom and Europe look to 3D printing for customization. IEEE Pulse 4: 22-26.

15. Al-Juboori MJ, bin Abdulrahaman S, Dawood HF (2012) Principles of flap design in dental implantology. Dent Implantol Update 6: 41-44.

16. Romanos GE (2010) Periosteal releasing incision for successful coverage of augmented sites. A technical note. J Oral Implantol 36: 25-30.

17. Cho EH, Park JC, Cha JK, Kim YT, Jung UW, et al. (2011) Dimensiona change of the healed periosteum on surgically created defects. J Periodontal Implant Sci 41: 176-184

18. Szymor P, Kozakiewicz M, Olszewski R (2016) Accuracy of open-source softwaresegmentation and paper-based printed three-dimensional models. $J$ Craniomaxillofal Surg 44: 202-209. 